Research Article

\title{
Konjac Sponge Derived Carbon Flakes with Optimized Pore Structure for High-Performance Supercapacitor
}

\author{
Bing Han $(\mathbb{D}$, Chongchong Geng $\mathbb{D}$, and Gong Cheng $\mathbb{i}$ \\ College of Environmental Science and Engineering, North China Electric Power University, Beijing 102206, China \\ Correspondence should be addressed to Bing Han; hanbing01@ncepu.edu.cn
}

Received 10 August 2018; Accepted 25 September 2018; Published 31 October 2018

Guest Editor: Mengyu Yan

Copyright (c) 2018 Bing Han et al. This is an open access article distributed under the Creative Commons Attribution License, which permits unrestricted use, distribution, and reproduction in any medium, provided the original work is properly cited.

\begin{abstract}
Lamellar activated carbons derived from Konjac sponges (KACs) have been successfully fabricated through a facile $\mathrm{KOH}$ activation method. By manipulating the activation temperature and $\mathrm{KOH} / \mathrm{C}$ ratio, the achieved $\mathrm{KACs}$ exhibit ultrahigh specific surface area up to $\sim 3000 \mathrm{~m}^{2} / \mathrm{g}$ and hierarchical pore structure with tunable micro/mesopore distribution. Notably, KACs possess plenty of worm-shaped micropores formed by graphene stacking layers with the lateral distance close to size of hydrated electrolyte ions. Owing to optimized pore structure, high graphitization, and extra $\mathrm{O} / \mathrm{N}$ doping, KACs exhibited much enhanced specific capacitance $(253.0 \mathrm{~F} / \mathrm{g})$, superior rate ability $(77 \%$ retention of capacitance at $10 \mathrm{~A} / \mathrm{g}$ ), and remarkable cycling stability $(0.4 \%$ decay under $5 \mathrm{~A} / \mathrm{g}$ after 2000 cycles) in the acid electrolyte. The mass production ability of KAC materials and the knowledge of correlation between texture properties and capacitive performance open new opportunities for the application of such novel biomass-derived carbons in supercapacitor devices.
\end{abstract}

\section{Introduction}

The shortage of fossil fuels and booming demand for sustainable energy call for the development of highly efficient energy storage solutions $[1,2]$. Supercapacitors (SCs), as a complementary or independent charge storage system for electric vehicles or regenerated applications, have exhibited bright prospect due to the high power density, fast charging process, and excellent cycling performance [3]. Based on the surface adsorption/desorption of electrolyte ions, electrochemical double-layer capacitors (EDLCs) are one important component of commercial electrochemical capacitors owing to their low cost and high operation safeties [4]. Nevertheless, the relatively low-energy density of EDLCs has restricted their further application. Therefore, much efforts have been made to increase the energy storage capability of EDLCs in recent years [5, 6]. One of the most effective strategies is to improve the specific capacitance through sophisticated design of electrode materials. Carbon nanomaterials are the dominant electrode materials for EDLCs. The past few decades have witnessed the development of various nanostructured carbon materials in SCs, ranging from the modified activated carbons (ACs) [7] to novel carbon nanostructures based on carbon nanotube [8], graphene [9], or metal-organic framework- (MOF-) derived carbon [10].

ACs, by contrast, have been the mainstream electrode material in commercial SC devices due to the cost-effective and easy to scale up nature. To satisfy the demand of next generation SCs for both high-specific capacitance and rate ability, rational design of pore distribution/structure and optimization of surface modification have been urgently required for ACs while maintaining the considerable specific surface area (SSA) [11-13]. On one hand, micropores (pore size $<2.0 \mathrm{~nm}$ ) provide effective sites for ion adsorptiondesorption, and mesopores $(2.0 \mathrm{~nm}<$ pore size $<50 \mathrm{~nm})$ play a dominant role in ion transportation [14]. Moreover, several studies have demonstrated the importance of subnanopores (pore size $<1.0 \mathrm{~nm}$ ) in largely increasing capacitance when the pore dimension matches the radius of the electrolyte ions $[15,16]$, which inspired attention on further optimizing the hierarchical pore structure. On the other hand, heteroatom $(\mathrm{N}, \mathrm{O}, \mathrm{S}$, etc.) doping or group functionalization could produce surface redox reaction, therefore improving the accessibility by optimizing the wettability and introducing specific pseudocapacitance $[13,17,18]$. 
Furthermore, manipulation of the graphitization degree would increase the electrical conductivity, which facilitates the charge transfer especially at high rate $[19,20]$. Therefore, development of well-designed ACs with high SSA, welldesigned pore structure, heteroatom doping, and high graphitization degree opens new opportunities for this sort of traditional materials in future SC devices. Notably, biomass is an excellent precursor with the advantages of large amount, rich composition, and distinct primary texture [21]. Upon appropriate activation process, hierarchically porous ACs which inherit the original microstructure and heteroatom can be achieved [22, 23]. Thus, selection of appropriate carbon precursor and optimization of activation condition become the research hotspot in nowadays.

Konjac, which is composed of glucomannan with $\mathrm{D}$-mannose and $i$-glucose in $\mathrm{b}(1,4)$ linkages, has been widely used as an agent for food ingredient in Asia [24]. Due to its low cost, easy for gelation, and good biocompatibility, Konjac glucomannan (KGM) has served as a gelling, texturizing, and film-forming agent in industries such as food, drug, and cosmetic [25]. Nevertheless, the application of ACs derived from Konjac-derived ACs in SCs has been rarely reported. Li et al. have demonstrated the first study of Konjac gel-derived porous biochar as electrode active materials in SCs, which exhibited the specific capacitance of $273.8 \mathrm{~F} / \mathrm{g}$ at $1 \mathrm{~A} / \mathrm{g}$ in $1 \mathrm{M} \mathrm{KOH}$ [26]. Additionally, "snow Konjac" is a sponge-like Konjac product consisting of KGM and rice flour (mass ratio of $\sim 1: 1$ ) as main gradients. Taking advantages of the viscosity of KGM and swelling property of rice flour, such Konjac sponges process a loose and porous appearance with lamellar inner wall, which are expected to serve as a novel platform to achieve new structured ACs. Herein, we fabricated two-dimensional (2-D) graphitized carbon nanosheets from the Konjac sponge through the facile $\mathrm{KOH}$ activation method. By tuning the carbonization temperature and $\mathrm{KOH} / \mathrm{C}$ ratio, Konjac sponge-derived ACs (KACs) with ultrahigh SSA (up to $\sim 3000 \mathrm{~m}^{2} / \mathrm{g}$ at $\mathrm{KOH} / \mathrm{C}>$ 3 ), tunable micro/mesopore volume, varied $\mathrm{O} / \mathrm{N}$ doping, and high graphitization degree have been achieved. Impressively, such 2-D KAC nanosheets show hierarchical pore structure with coexistence of micro/mesopores. Especially, the micropores contain large amount of worm-shaped graphene stacking layers with the lateral distance close to the size of hydrated electrolyte ions, which greatly benefit the capacitive performance. Therefore, compared with nonactivated samples, KACs exhibited much enhanced specific capacitance, superior rate ability, and remarkable cycling stability in acid electrolyte. The relationship between the capacitive performance (specific capacitance and rate ability) and the texture property (SSA, micropore volume, and mesopore volume) as well as the graphitization degree is also elucidated, which would largely benefit the design and practical application of such KAC materials in SCs.

\section{Materials and Methods}

2.1. Chemicals. The Konjac sponge with the brand "Leshan" was bought from Jingdong Mall. Potassium hydroxide $(\mathrm{KOH})$ and hydrochloric acid $(\mathrm{HCl})$ used were obtained from Aladdin (Shanghai, China). N-methylpyrrolidinone (NMP) was bought from Alfa Aesar.

\subsection{Fabrication of Hierarchical Porous Carbon from Konjac} Sponge. The Konjac sponge was firstly crushed and precarbonized in the tube furnace under $\mathrm{N}_{2}$ atmosphere at $500^{\circ} \mathrm{C}$ for $2 \mathrm{~h}$, and the achieved sample was mixed thoroughly with $\mathrm{KOH}(\mathrm{C} / \mathrm{KOH}$ ratio of $1: 3)$. The mixture was then carbonized under $\mathrm{N}_{2}$ flow at $700^{\circ} \mathrm{C}, 800^{\circ} \mathrm{C}$, and $900^{\circ} \mathrm{C}$ for $2 \mathrm{~h}$. The resultant products were marked as Konjac derived activated carbon (KAC)- 700, 800, and 900, respectively. The precarbonized sample carbonized under $700^{\circ} \mathrm{C}$ without the addition of $\mathrm{KOH}$ was denoted as UAC. To evaluate the effect of carbonized temperature on the capacitive performance, the precarbonized carbon was mixed with different $\mathrm{C} / \mathrm{KOH}$ ratios $(1: 1,1: 2$, and $1: 4)$ before the further carbonization at $800^{\circ} \mathrm{C}$ under $\mathrm{N}_{2}$ atmosphere. The derived samples were denoted as KAC-1, 2, and 4, respectively. KAC-800 was equal to KAC-3. All the KAC samples were washed with $2 \mathrm{M} \mathrm{HCl}$ to remove the residual $\mathrm{KOH}$ and centrifuged with deionized water until the solution reached neutral condition. After drying in vacuum, the KAC materials were obtained. The synthetic process is shown in Scheme 1.

2.3. Characterization. The morphology and high-resolution imaging were obtained from a Tecnai G2 F20 U-TWIN. Material phase analysis was conducted using an X-ray diffractometer (D/max-TTRIII). Information of chemical and elemental composition was achieved from X-ray photoelectron spectroscopy (XPS). Raman analysis was performed on a Renishaw inVia plus system at $513 \mathrm{~nm}$ laser excitation. Texture and pore information were recognized based on $\mathrm{N}_{2}$ adsorption-desorption isotherms from a Micromeritics ASAP 2010 analyzer.

2.4. Electrochemical Testing. The potential of KAC-based samples as SC electrode materials was evaluated on a CHI660E workstation. The related measurements were performed through a three-electrode system with an electrolyte of $1 \mathrm{M} \mathrm{H}_{2} \mathrm{SO}_{4}$. KAC-based samples (KAC-700, 800, and 900 and KAC-1 and 2) were ground with specific amount of acetylene black and polyvinylidene fluoride (mass percentage is $8: 1: 1$ ) in $N$-methyl pyrrolidone (NMP) to form slurry, which was dispensed on graphite flake to form an area of $1 \mathrm{~cm} \times 1 \mathrm{~cm}$. The electrodes were dried in vacuum $\left(80^{\circ} \mathrm{C}, 12 \mathrm{~h}\right)$. The mass loading was obtained by measuring the mass of the blank substrate and the dried working electrode. The Pt plate counterelectrode, as a prepared working electrode, and $\mathrm{Hg} / \mathrm{Hg}_{2} \mathrm{SO}_{4}$ reference electrode formed the three-electrode system. Cyclic voltammetry (CV) and galvanostatic charge-discharge (GCD) results were achieved in the potential scope of $-0.6 \sim 0.3 \mathrm{~V}$. Electrochemical impedance spectra (EIS) were achieved under the condition of $5 \mathrm{mV}$ and $100 \mathrm{kHz} 0.01 \mathrm{~Hz}$. The specific capacitance (Cs, F/g) was calculated based on the GCD curve according to the following equation: 


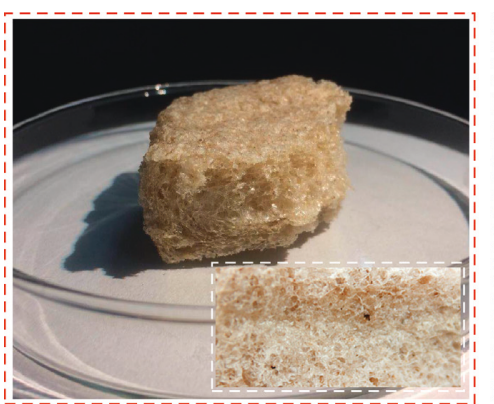

Konjac sponge
Crushing Carbonization

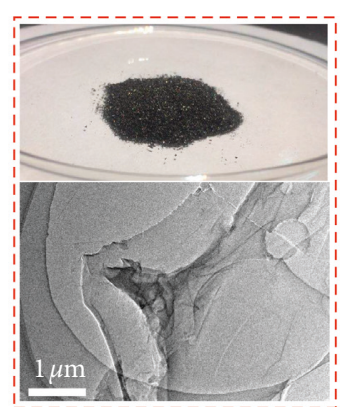

Biomass carbon
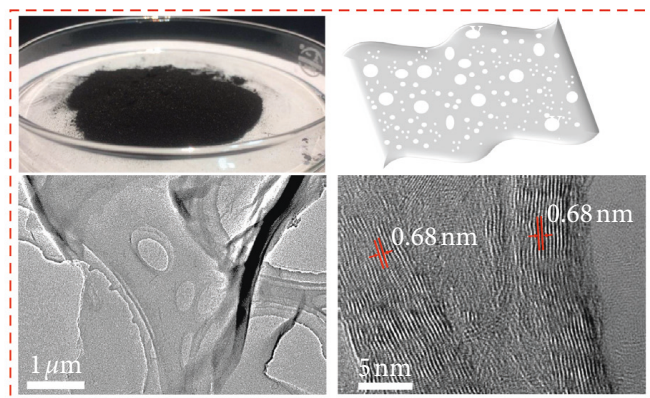

2-D hierarchical porous graphitized carbon

Scheme 1: The synthetic procedures for hierarchical porous KAC materials.

$$
\mathrm{Cs}=\frac{I t}{\Delta V m},
$$

where $I$ and $t$ are the charge-discharge current and discharging time, respectively, $\Delta V$ is the potential range, and $m$ is the mass of the active material.

\section{Results and Discussion}

The pristine Konjac sponge precursor possessed laminar network structure in macroscopic view. TEM imaging provided intuitional information about the morphology and porous structure of the samples. As shown in Figure S1, the UAC sample exhibited very thin lamellar structure upon crushing and carbonization. The enlarged HR-TEM images indicated the amorphous nature of the nonactivated carbon flakes, which contained nanosized pores. In contrast, $\mathrm{KOH}$ activation gave rise to tremendous modification towards the KACs both in microstructure and graphitization. Interestingly, worm-shaped graphene bunches and amorphous area coexisted in KAC-based samples (Figures 1 and S2). The distance between graphene layers was 0.67 and $0.68 \mathrm{~nm}$ in KAC-700 and KAC-900, respectively (Figure S3). KAC-800 was dominated by the distorted short-range ordered crystalline with a lateral distance of $\sim 0.67$ and $\sim 0.79 \mathrm{~nm}$. As shown in Figure S4, staking graphene layers with larger lateral distance were clearly observed in KAC-1 $(0.79 \mathrm{~nm}), \mathrm{KAC}-2(0.85 \mathrm{~nm})$, and KAC-4 $(0.75 \mathrm{~nm})$. The enlargement of interlayer spacing for KAC-700 was further confirmed from selected-area electron diffraction (SAED) pattern (Figure S5(a)). Compared with the amorphous UAC carbon, the graphene crystallization zone indicated the increased graphitization of the KAC samples, which would largely benefit the capacitive performance arising from better electrical conductivity. Notably, the $\mathrm{KOH}$ etching effect became particularly obvious at a high temperature of $900^{\circ} \mathrm{C}$ and a high $\mathrm{KOH} / \mathrm{C}$ ratio of $4: 1$, with the observation of the rough surface and plentiful mesopores. The negligible observation of the change of carbon lattice distances for KAC4 may be due to the less-ordered crystalline area from the existence of great deal of mesopores (Figure S5(b)). Therefore, the hierarchical porous structure consisting of large amount of graphene layer subnanopore and a portion of mesopores formed due to activation process.
Furthermore, the XRD pattern of UAC showed broad peaks at $2 \theta=23^{\circ}$ and $43^{\circ}$ (Figure $2(\mathrm{a})$ ), corresponding to the diffraction signal of (002) and (101) plane of amorphous carbon $[27,28]$. KAC-based samples, in comparison, exhibited a negligible peak at $23^{\circ}$ and largely reduced diffraction at $43^{\circ}$ (Figures 2(a) and 2(b)), suggesting the rearrangement of the original amorphous carbon and introduction of large amount of pores. The steep increase in low-angle scatter in KAC samples compared with UAC originates from the enriched micro/mesopores [29]. As is shown in HRTEM, the graphene interlayer distance was much larger than the graphite (002) d-spacing of $0.34 \mathrm{~nm}$, which may arise from the separation effect due to $\mathrm{K}$ insertion/ intercalation into graphene layers [30]. The Raman spectra quantitatively demonstrate the graphitization degree of carbon materials (Figures 2(c) and 2(d)). KAC samples showed two Raman peaks at $1357 \mathrm{~cm}^{-1}$ and $1594 \mathrm{~cm}^{-1}$ characteristic of polycrystalline and crystal graphite, respectively [31, 32]. The intensity ratio of D-band and G-band $\left(I_{\mathrm{D}} / I_{\mathrm{G}}\right)$ for KAC700,800 , and 900 is $0.96,0.96$, and 1.00 , respectively, while that for KAC-1, 2, and 4 were $0.95,0.99$, and 0.74 . The much lower $I_{\mathrm{D}} / I_{\mathrm{G}}$ value of KAC samples compared with commercial activated carbon $(\sim 1.92)$ demonstrated the high graphitization degree [33]. This result also illustrated that the disorder degree of carbon increased with the carbonization temperature. The sharper peak with temperature and $\mathrm{KOH} / \mathrm{C}$ was consistent with the larger graphene separation observed from HRTEM images. On one hand, the high content of defective carbon provided more active sites or active surface areas, giving rise to improved capacitance. On the other hand, graphitized carbon increases the electric conductivity which benefited the rate capability [20]. Therefore, the optimized capacitive performance is called for the good intercoordination of both effects.

XPS spectra further provided the chemical composition and element binding information. As shown in Figure 3, the high-resolution $\mathrm{C} 1 \mathrm{~s}$ spectra of KAC-based samples consisted of a peak centered at $284.7 \mathrm{eV}$ with small tail at the high-binding energy side and a shoulder peak in the range of 288.0 292.8 eV. The former peak can be deconvoluted into $\mathrm{sp}^{2}$-bonded carbon $(284.7 \mathrm{eV})$ with a small tail containing $\mathrm{sp}^{3}$-bonded carbon $(285.8 \mathrm{eV})$. The shoulder peak consisted of three individual component peaks, corresponding to 


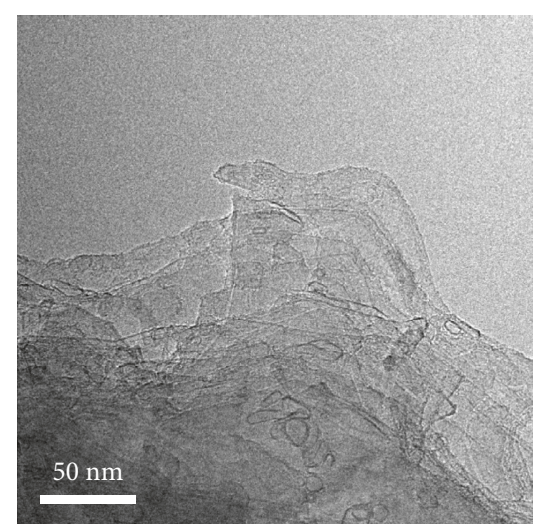

(a)

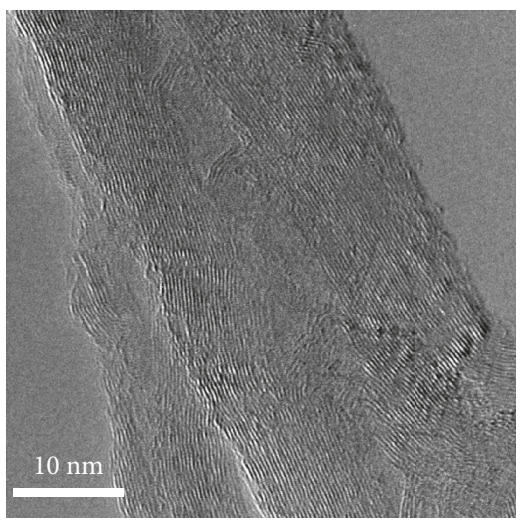

(d)

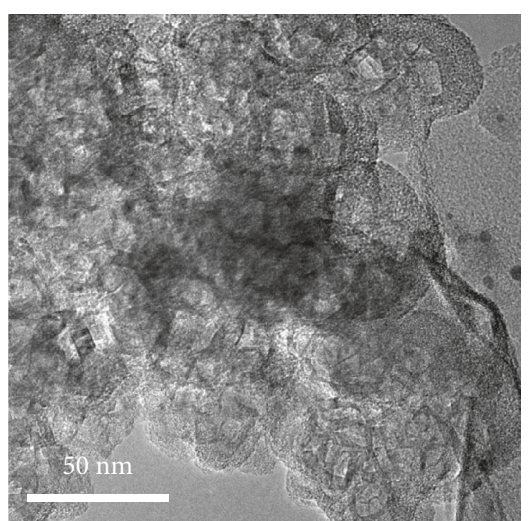

(b)

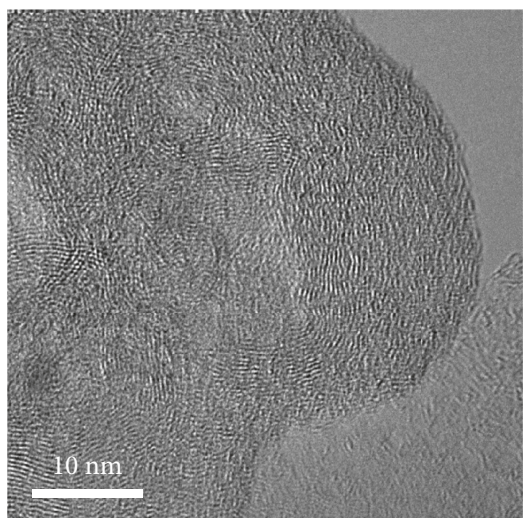

(e)

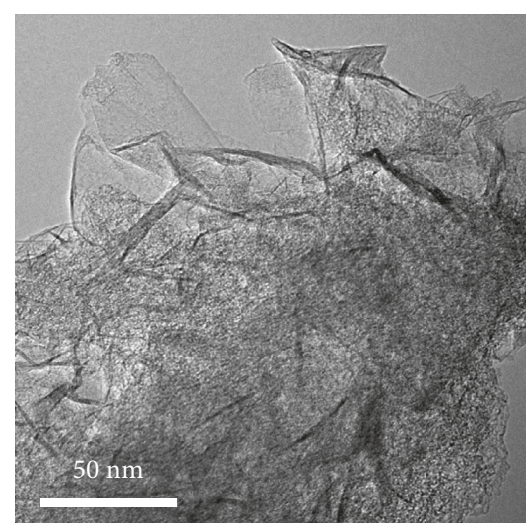

(c)

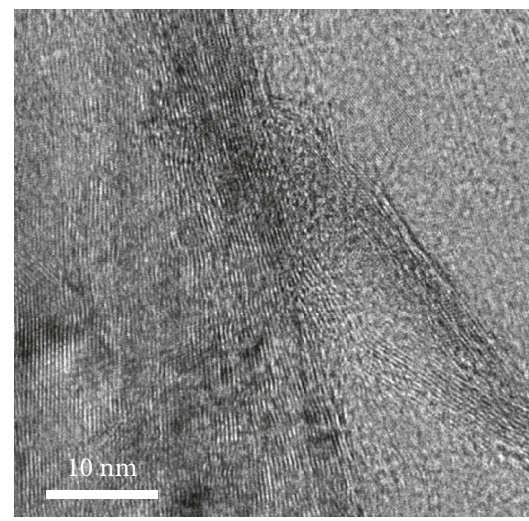

(f)

FIgURE 1: Transmission electron microscopy (TEM) images of (a, d) KAC-700, (b, e) KAC-800, and (c, f) KAC-900.

carbonyl group $\mathrm{C}=\mathrm{O}(287.0 \mathrm{eV})$, carboxyl $\mathrm{O}-\mathrm{C}=\mathrm{O}(289.2 \mathrm{eV})$, and a satellite peak of $\pi-\pi^{*}(291.4 \mathrm{eV})$, respectively [34, 35]. The overwhelmingly strong peak of $\mathrm{sp}^{2}$ carbon demonstrated the formation of graphene-like carbon sheets with high graphitization, which agreed well with the Raman results. As shown in Figure S6, O1s spectra of KAC-based samples indicated the presence of $\mathrm{C}=\mathrm{O}$ quinone-type groups (O-I), $\mathrm{C}-\mathrm{OH}$ phenol groups and/or $\mathrm{C}-\mathrm{O}-\mathrm{C}$ ether groups (O-II), and chemisorbed oxygen ( $\mathrm{COOH}$ carboxylic groups) and/or water (O-III), respectively [36]. Table S1 shows that KACs were composed of $\mathrm{C}$ and $\mathrm{O}$ and trace amount of $\mathrm{N}$. With the activation temperature and the $\mathrm{KOH} / \mathrm{C}$ ratio increasing, the content of carbon increased and the oxygen decreased (Table S1). The decreased total intensity of oxygenated groups is also observed from Figure S6. The existence of carbonyl/carboxyl groups and small amount of $\mathrm{N}$ benefited the improvement of the wettability, therefore facilitating the accessibility of the electrolyte ions. Also, the oxygenated groups provided pseudocapacitance for the EDLC-dominated capacitance of KAC-based samples [37].

As is revealed from TEM images, $\mathrm{KOH}$ etching process produced abundant hierarchical pores in the Konjac-derived carbon substrate. Therefore, BET characterization was conducted to further evaluate the texture properties and the effect of $\mathrm{KOH}$ amount and activation temperature on the pore structure of KAC materials. As shown in Figures 4(a) and 4(c), UAC and all the KAC samples exhibited steep $\mathrm{N}_{2}$ adsorption at very low relative pressure $\left(p / p_{0}\right)$, which was the characteristic of the type-I isotherm [38]. This result indicated the existence of large amount of micropores in these samples. Notably, KAC-900 and KAC-4 possessed a $\mathrm{H}_{4}$-type hysteresis loop at $p / p_{0}>0.4$, suggesting the presence of mesopores [11]. The pore size distribution curves (Figure 4(b)) showed that all KAC-700, 800, and 900 samples possessed subnanopores centered at $\sim 0.68$ and $0.80 \mathrm{~nm}$, respectively. This was consistent with the lateral distance achieved from HRTEM images. Along with the subnanopores, large micropores of $\sim 1.20 \mathrm{~nm}$ and large amount of mesopores coexisted in these samples. KAC-900 exhibited larger mesopores $(\sim 2.60 \mathrm{~nm})$ than $\mathrm{KAC}-700$ and 800 $(\sim 2.0 \mathrm{~nm})$. In contrast, UAC only showed a pore peak centered at $\sim 1.17 \mathrm{~nm}$ with very low pore volume, indicating the introduction of both subnanopores and mesopores through the $\mathrm{KOH}$ activation process. Moreover, changing the $\mathrm{KOH} / \mathrm{C}$ could also modulate the pore structure of KAC materials. KAC-1 and 2 showed similar pore distribution with KAC-800, while KAC-4 exhibited obvious introduction of enlarged mesopores of 2.76 and $3.42 \mathrm{~nm}$ (Figure 4(d)). Previous studies evidenced that subnanopores with the size matching up with that of electrolyte ions could greatly enhance the specific capacitance $[15,39,40]$. Considering the reported size of hydrated $\mathrm{SO}_{4}{ }^{2-}$ ion $(0.533 \mathrm{~nm})$ [41, 42], KAC-700, KAC-2, and KAC-3 containing large fraction of subnanopore sized at $\sim 0.68 \mathrm{~nm}$ were expected to have highly 

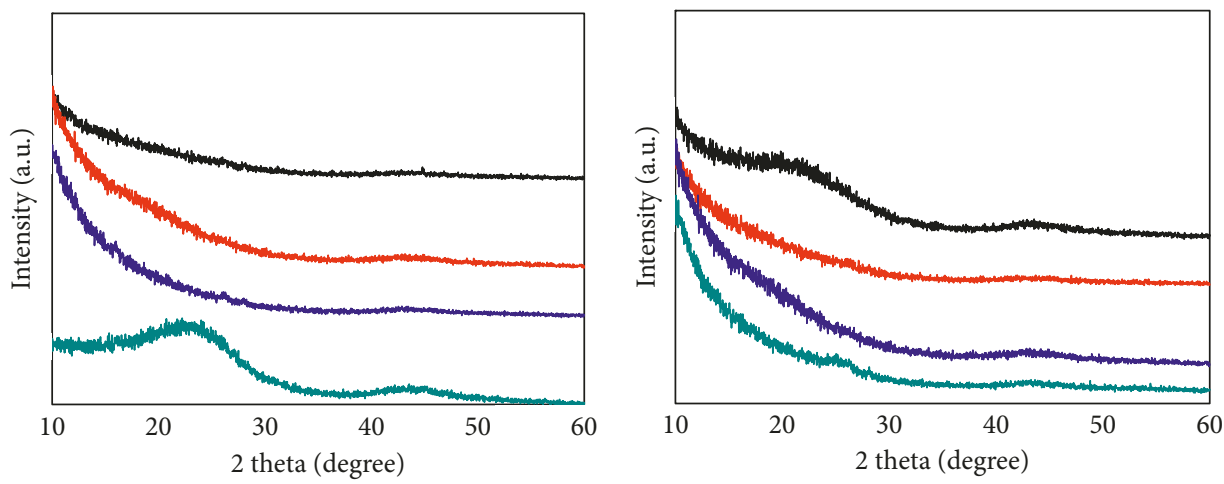

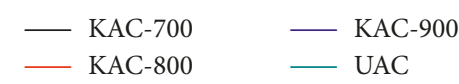

(a)

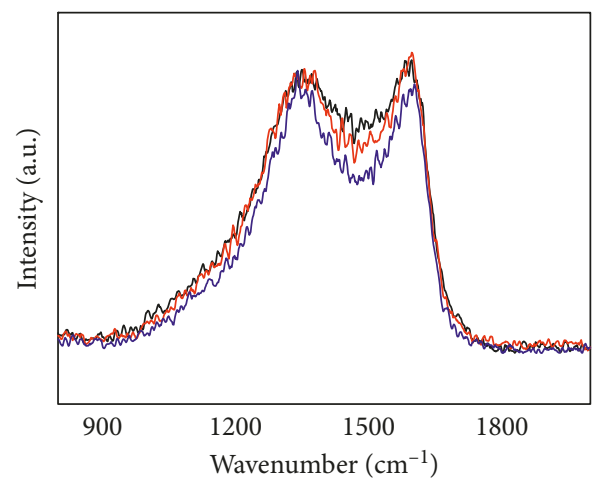

— KAC-700

— KAC-800

— KAC-900
- KAC-1

- KAC-2

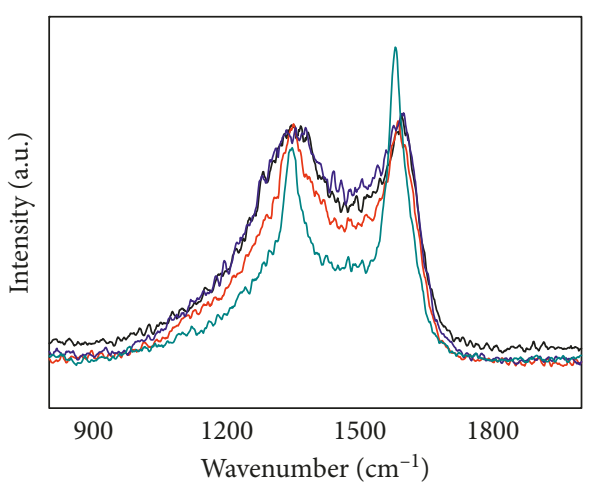

KAC-1

KAC-2

- KAC-3

- KAC-4

(d)

(c)

FIGURE 2: XRD patterns of KAC materials activated under (a) different temperatures and (b) different KOH/C ratios in comparison with UAC, (c) and (d) Raman spectra of KAC-based materials.

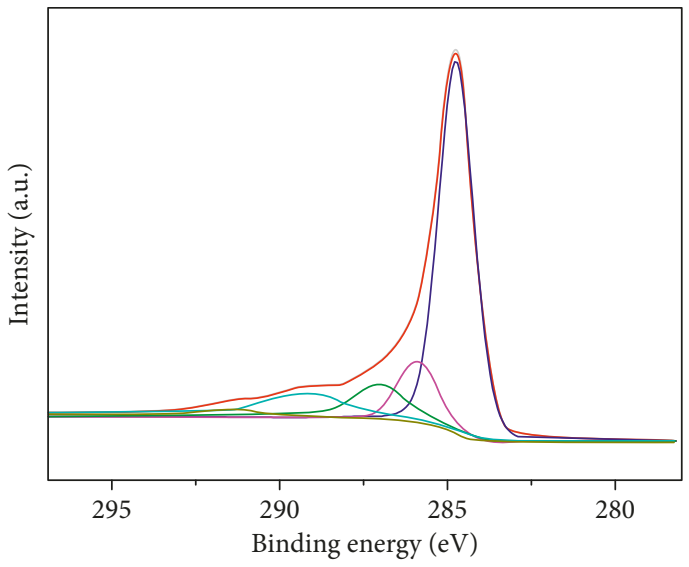

KAC-700 C1s
- Raw
- $\mathrm{C}=\mathrm{O}$
- Fitted
$-\mathrm{sp}^{2}-\mathrm{C}$
$-\mathrm{sp}^{3}-\mathrm{C}$

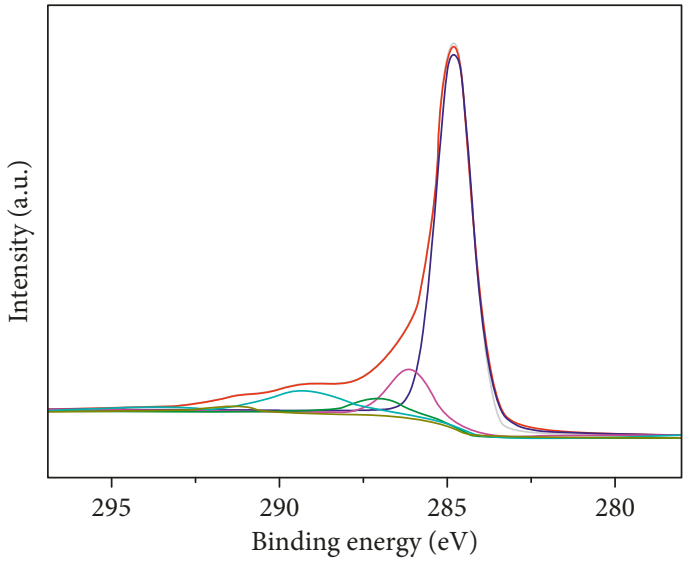

KAC-800 C1s

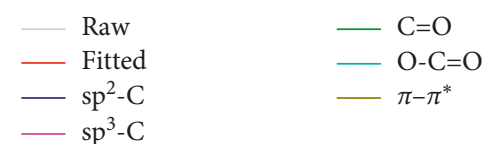

(b)

Figure 3: Continued. 

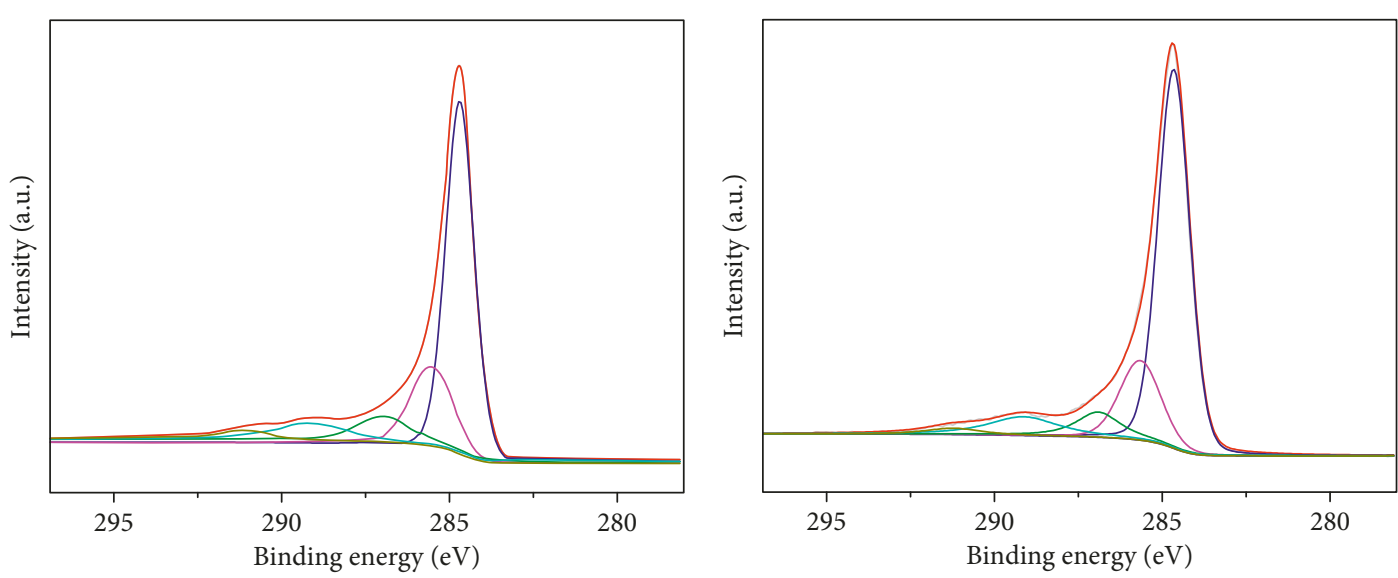

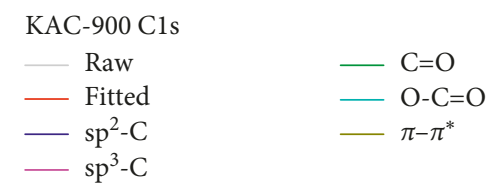

(c)

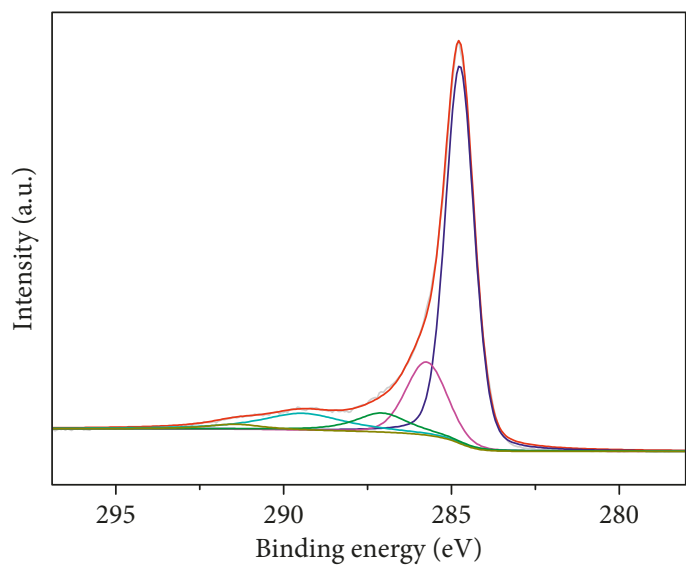

KAC-2 C1s

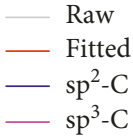

$$
\begin{aligned}
& -\mathrm{C}=\mathrm{O} \\
& -\mathrm{O}-\mathrm{C}=\mathrm{O} \\
& \pi-\pi^{*}
\end{aligned}
$$

(e)

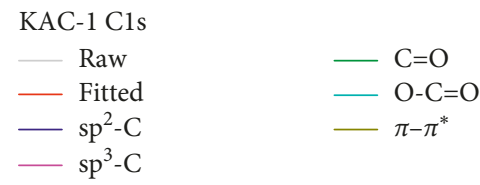

(d)
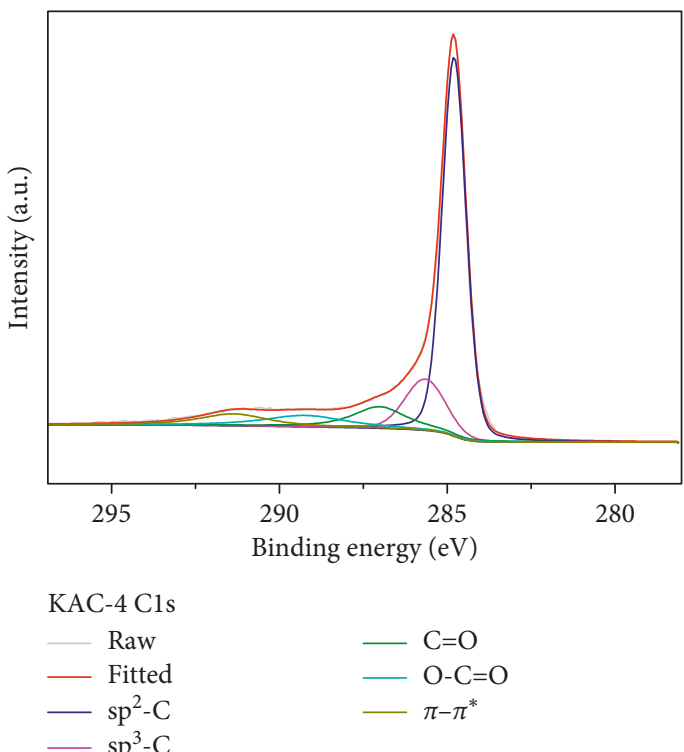

(f)

FiguRE 3: XPS C1s spectra of KAC-based samples.

effective surface area for ion adsorption-desorption, yielding improved specific capacitance. The worm-shaped pores formed from the carbon layers also contributed to the enhanced energy storage capability [43]. Despite the absence of macropores, the thin lamellar KAC materials would shorten the ion transportation route which reduced the diffusion impedance. Detailed specific surface area (SSA) and pore volume statistics are summarized in Table 1 . At $\mathrm{KOH} / \mathrm{C}=3$, KAC materials possessed ultrahigh SSA up to $\sim 3117 \mathrm{~m}^{2} / \mathrm{g}$ (KAC-700 and 900), which was about $\sim 21$ times and $\sim 1.9$ times higher than UAC and commercial-activated carbon, respectively. This result evidenced the efficiency of etching reaction between $\mathrm{KOH}$ and $\mathrm{C}$ precursor $(6 \mathrm{KOH}+\mathrm{C} \leftrightarrow 2 \mathrm{~K}+$ $\left.3 \mathrm{H}_{2}+2 \mathrm{~K}_{2} \mathrm{CO}_{3}\right)[29,44]$. As the ratio increases, SSA based on the BET model $\left(S_{\mathrm{BET}}\right)$ increased. With $\mathrm{KOH} / \mathrm{C}$ ratio larger than $3: 1$, SSA did not change much with the increase of the ratio or the carbonization temperature. But the pore structure including the distribution and relevant pore volume of micropores and mesopores exhibited large differences (Table 1). According to the density functional theory (DFT) method, KAC samples achieved at lower carbonization temperature $\left(700\right.$ and $\left.800^{\circ} \mathrm{C}\right)$ and low $\mathrm{KOH} / \mathrm{C}$ ratio (1:1 and 2:1) showed SSA with 90\% 93\% contribution from micropores. Nevertheless, the portion of micropores decreased to $71 \%$ and $56 \%$ under the formation of mesopores for KAC-900 and KAC-4, respectively. The pore volume was also an important parameter to evaluate the capacitance and rate ability of EDLC-type SCs. Compared with the UAC sample, the $\mathrm{KOH}$ activation process under different conditions gave rise to the KAC materials with 


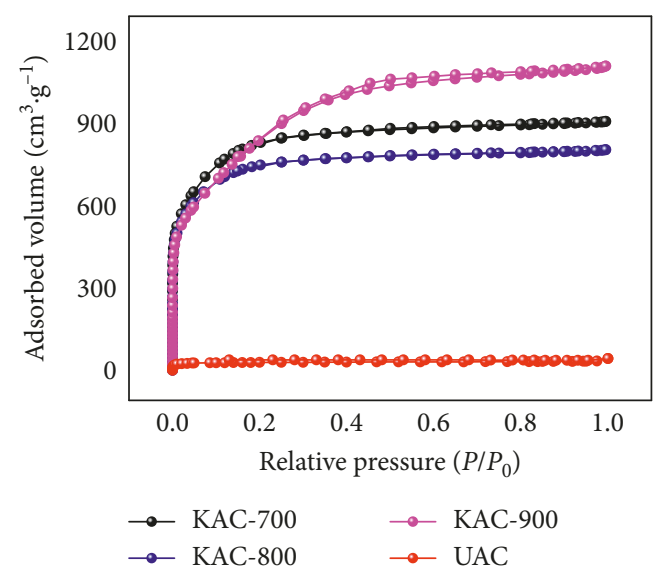

(a)

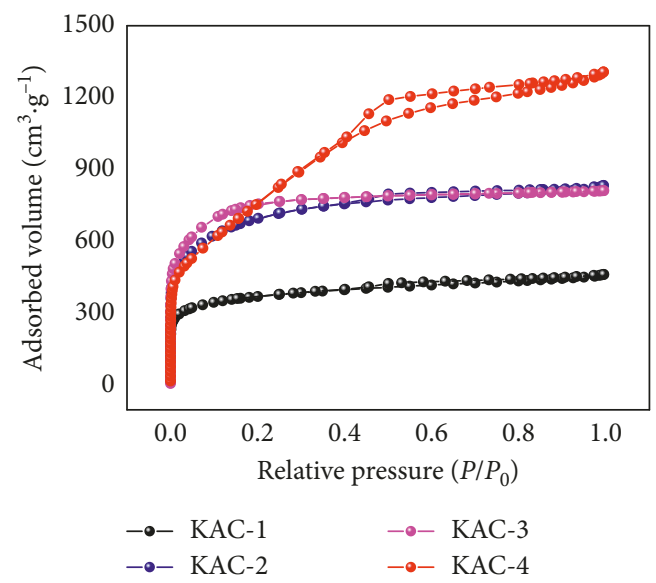

(c)

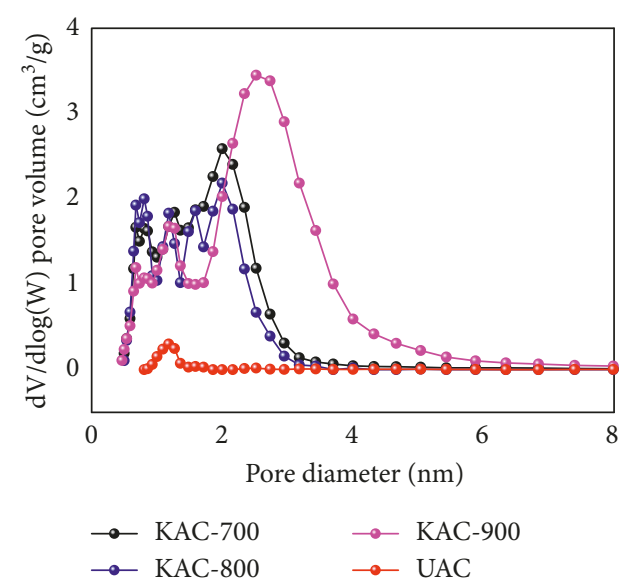

(b)

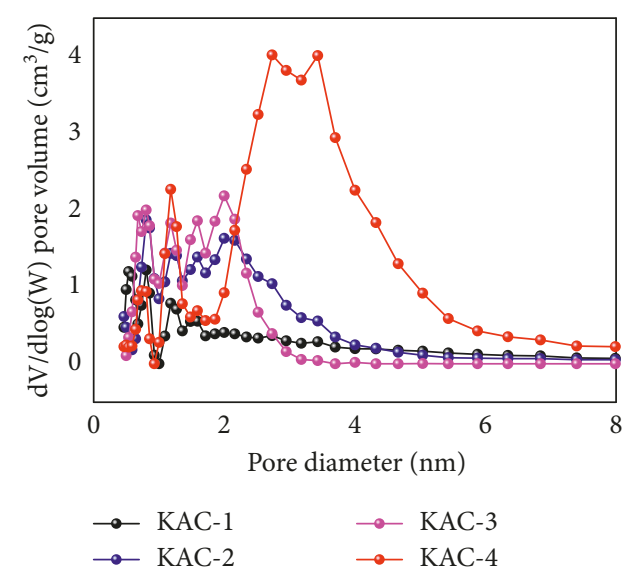

(d)

FIGURE 4: Nitrogen adsorption/desorption isotherms (a, c) and DFT pore size distribution curve (b, d) of KAC-based samples in comparison with UAC.

TABLE 1: Texture properties of the KAC samples achieved under different conditions and UAC. ${ }^{\mathrm{a}}$

\begin{tabular}{|c|c|c|c|c|c|c|c|c|}
\hline \multirow{2}{*}{ Sample } & \multirow{2}{*}{$S_{\mathrm{BET}}\left(\mathrm{m}^{2} / \mathrm{g}\right)$} & \multirow{2}{*}{$S_{\mathrm{DFT}}\left(\mathrm{m}^{2} / \mathrm{g}\right)$} & \multicolumn{3}{|c|}{$S_{\text {DFT }}\left(\mathrm{m}^{2} / \mathrm{g}\right)$} & \multicolumn{3}{|c|}{ Pore vol $\left(\mathrm{cm}^{3} / \mathrm{g}\right)$} \\
\hline & & & $d<2 \mathrm{~nm}$ & $d<2 \mathrm{~nm}$ & $\mathrm{SSA}_{\text {mic }}(\%)$ & $d<2 \mathrm{~nm}$ & $d>2 \mathrm{~nm}$ & $V_{\text {mes }} / V_{\text {mic }}$ \\
\hline KAC-700 & 3117 & 1952 & 1757 & 195 & 90 & 0.94 & 0.24 & 0.25 \\
\hline KAC- 800 & 2841 & 1861 & 1731 & 126 & 93 & 0.88 & 0.16 & 0.18 \\
\hline KAC-900 & 3116 & 1895 & 1352 & 543 & 71 & 0.70 & 0.77 & 1.10 \\
\hline KAC-1 & 1382 & 1178 & 1094 & 84 & 93 & 0.43 & 0.16 & 0.37 \\
\hline KAC-2 & 2557 & 1612 & 1402 & 210 & 87 & 0.76 & 0.31 & 0.41 \\
\hline KAC-4 & 2888 & 1687 & 949 & 738 & 56 & 0.49 & 1.24 & 2.53 \\
\hline UAC & 152 & 70.5 & 68.3 & 2.2 & 97 & 0.05 & 0.005 & 0.10 \\
\hline
\end{tabular}

${ }^{a} S_{\text {BET }}$ and $S_{\text {DFT }}$ : the specific surface area (SSA) based on Brunauer-Emmett-Teller (BET) and density functional theory (DFT) method; SSA $A_{\text {mic: }}$ the microporous surface area; $V_{\text {mes }} / V_{\text {mic }}$ : the ratio between mesopore and micropore volume.

highly tunable pore structure. The KAC samples had very high pore volume compared with the biomass derived carbon counterparts $[34,45,46]$. Notably, KAC-700 possessed the highest micropore volume of $0.94 \mathrm{~cm}^{3} / \mathrm{g}$ while $\mathrm{KAC}-4$ had the highest ratio between mesopore and micropore volume up to 2.56. The large microporous SSA and pore volume would benefit the charge storage capability due to high electroadsorption interaction between electrolyte ions and accessible pore surface. The high ratio of $V_{\text {mes }} / V_{\text {mic }}$ guaranteed the high-rate transportation of ions from solution to the active surface with the large fraction of mesopores acting as ion channels [47]. Therefore, the above results indicated the advantage of the Konjac sponge as the precursor for activated biomass carbon materials, and the efficiency of $\mathrm{KOH}$ etching treatment in providing optimized SC electrode materials with modulated SSA and pore structure. The series of KAC samples not only provided excellent model materials for studying the dependence of 
supercapacitor performance on the structural properties of carbon materials but also paved the way for desirable carbon materials for high-performance SCs.

The capacitive performance of KACs as electrode materials for SC application was tested in the aqueous solution of $1 \mathrm{M}$ $\mathrm{H}_{2} \mathrm{SO}_{4}$. As shown in Figures 5(a), 6(a), and S7, all KAC samples exhibited rectangular-shaped CV curves at $5 \mathrm{mV} / \mathrm{s}$ and showed little deviation with the scan speed up to $100 \mathrm{mV} / \mathrm{s}$, indicating the ideal EDLC behavior of the electrodes. The symmetric and triangular charge-discharge curves provided further confirmation for the good rate performance (Figures 5(b), 6(b), and S7). The small humps in CV curves originated from the pseudocapacitance due to $\mathrm{O} / \mathrm{N}$-heteroatom doping. It can be obviously noticed that $\mathrm{KOH}$-activated carbons showed tremendously enhanced specific capacitance in comparison with UAC. The exact capacitance value was determined from GCD data (Table S2). When tuning the activation temperature, KAC700 possessed the largest capacitance $(235.1 \mathrm{~F} / \mathrm{g})$ at $0.5 \mathrm{~A} / \mathrm{g}$. Upon tuning the $\mathrm{KOH} / \mathrm{C}$ ratio, $\mathrm{KAC}-2$ and $\mathrm{KAC}-3$ showed larger capacitance of 227.0 and $223.0 \mathrm{~F} / \mathrm{g}$, respectively. In overall, the modulation of $\mathrm{KOH}$ activation condition towards capacitance can be understood based on the previous analysis of pore information. KAC-700 had the largest microporous SSA $\left(1754 \mathrm{~m}^{2} / \mathrm{g}\right)$ and the maximum micropore volume $\left(0.94 \mathrm{~cm}^{3} / \mathrm{g}\right)$, followed by KAC- $800\left(S_{\text {mic }}=1731 \mathrm{~m}^{2} / \mathrm{g}\right.$ and $V_{\text {mic }}=0.88 \mathrm{~cm}^{3} / \mathrm{g}$ based on DFT calculation) and KAC-2 $\left(S_{\text {mic }}=1402 \mathrm{~m}^{2} / \mathrm{g}\right.$ and $\left.V_{\text {mic }}=0.76 \mathrm{~cm}^{3} / \mathrm{g}\right)$. The large microporous surface provided abundant active sites for trapping the electrolyte ions, which greatly benefited the energy storage. Moreover, the pore structure played an important role in improving the specific capacitance. On one hand, KAC-700, KAC-2, and KAC-3 contained large fraction of the subnanopore sized at $0.68 \mathrm{~nm}$. The well-fitted dimension with the electrolyte ion would benefit the energy storage [41, 42]. On the other hand, the moderate $I_{\mathrm{D}} / I_{\mathrm{G}}$ demonstrated the existence of the defective carbon, which increased the exposed active surface for better charge storage performance.

Furthermore, rate capability was also a very important property to evaluate the capacitive performance of materials. The dependence of specific capacitance on the current density is shown in Figures 5(c) and 6(c). KAC-900 and KAC- 4 showed remarkable capacitance retention of $\sim 77 \%$ with the current density increasing from $0.5 \mathrm{~A} / \mathrm{g}$ to $10 \mathrm{~A} / \mathrm{g}$, which was better than that of the rest KAC samples $(70 \%$ $72 \%)$. The GCD curves of the KAC samples under different current densities are shown in Figure S8. For UAC, 71.4\% of the original capacitance decayed at $10 \mathrm{~A} / \mathrm{g}$ (Figure S9). The previous study revealed that the rate capability was dominated by the mesopore/micropore volume ratio [11, 47]. As shown in Figure S10, the trend of rate performance for KACbased materials was in overall consistent with that of the $V_{\text {mes }} / V_{\text {mic }}$ values. The improved amount of mesopores in KAC-900 and KAC-4 served as ion transportation channels from the solution to the active surface of micropores, which guaranteed the smooth charge transfer at high-charge density [48]. Besides, the overall good rate performance of other KAC samples without much mesopores can be explained by the existence of large micropores sized at $\sim 1.20$ and $\sim 1.59 \mathrm{~nm}$, which were reported to facilitate the ion diffusion process such as mesopores [27, 49]. The high graphitization degree gave rise to good conductivity of KAC materials, therefore leading to fast electron transport with low resistance. Furthermore, the EIS measurement provided deeper insight into the impedance referring to the ion diffusion and charge transfer. The Nyquist plots of KAC samples (Figures 5(d) and 6(d)) consisted of a semicircle at the high frequency with the real-axis intercept, followed by the Warburg resistance in the mid-to-high frequency region and a steep line in the low-frequency region. The small value of the intercept indicated the low equivalent series resistance (ESR), which was in good agreement with the negligible IR drop in the discharging curves of all the KAC samples $[15,50]$. The semicircle diameter corresponded to the charge transfer resistance $\left(R_{\mathrm{ct}}\right)$ [46]. KAC-900 and KAC-4 showed very low $R_{\text {ct }}$ value of $\sim 0.11$ and $\sim 0.30 \mathrm{Ohm}$, respectively. Moreover, the shorter projected length of the $45^{\circ}$ Warburg diffusion line of KAC-900 and KAC-4 confirmed the reduced diffusion resistance of electrolyte ions owing to the mesopores and large micropores with high pore volume and graphene layers' pathways with large layer distance [37]. The above results confirmed the high capacitance retention of KAC-900 and KAC-4 at high rate. Notably, the extended spike in the low frequency was typical of capacitive behavior. The closer the straight line to $90^{\circ}$, the better the capacitive performance $[51,52]$. By combining pore structure characterization and EIS test, the tendency of specific capacitance and rate capability of KAC samples can be well understood. Our results were compared with previous studies, and the detailed literature review of the specific capacitance is shown in Table S3.

To evaluate the cycling stability of such Konjac-derived carbon materials, charge-discharge performance was tested on KAC-700 under $5 \mathrm{~A} / \mathrm{g}$ for 2000 cycles. Figure $7 \mathrm{dem}$ onstrates a very good cycling performance with $99.6 \%$ retention of the initial capacitance. The slight increased capacitance arose from the activation of surface in the early stage of the charge-discharge process. The inset images showed the stable charge/discharge curves from the very beginning to the last few cycles. The superior long-range cycling performance confirmed that KAC-based samples were excellent electrode materials for the applications of high-efficient and stable supercapacitors.

Above all, KAC-700 exhibited the highest specific capacitance while KAC-900 and KAC-4 showed the best rate capability among the series of KAC materials. Combining structure and composition analysis, the dependence of the capacitive performance on the texture properties and chemical composition can be revealed as follows. For KAC700 , the highest microporous volume $\left(0.94 \mathrm{~cm}^{3} / \mathrm{g}\right)$ provided plentiful active sites for ion storage. The optimized subnanopore $(\sim 0.68 \mathrm{~nm})$ further boosts the capacitance. The relatively low carbonization temperature maintained large amount of $\mathrm{O}$ and trace $\mathrm{N}$, giving rise to additive pseudocapacitance. For KAC-900 and KAC-4, high activation temperature and $\mathrm{KOH}$ dose introduced large amount of mesopores of 2.76 and $3.42 \mathrm{~nm}$ with narrow distribution, which act as the ion transfer channels and reduce the diffusion resistance. The volume ratio between mesopores and 

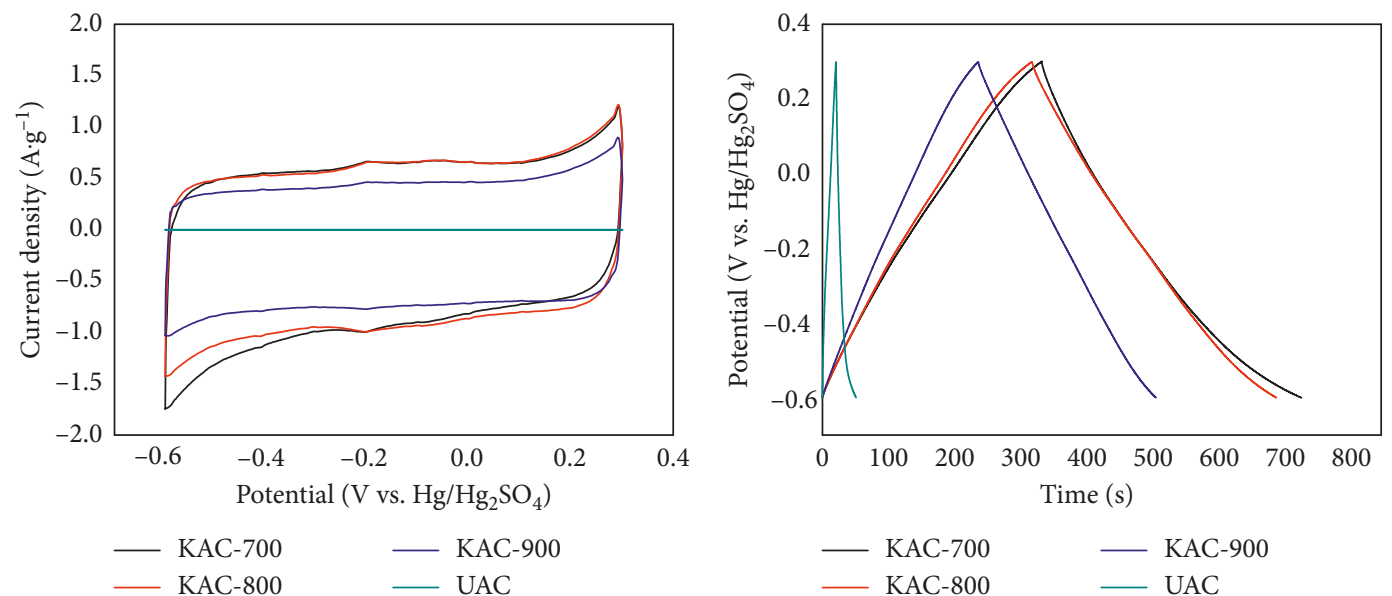

(b)


(c)

(d)

FIGURE 5: Electrochemical performance of KAC-700, 800, and 900 in $1 \mathrm{M} \mathrm{H}_{2} \mathrm{SO}_{4}$ aqueous solution. (a) CV curves at the scan rate of $5 \mathrm{mV} / \mathrm{s}$, (b) GCD curves at $0.5 \mathrm{~A} / \mathrm{g}$, (c) specific capacitances under different current densities calculated from GCD data, and (d) Nyquist plots of the achieved samples, the inset images show enlarged impedance at the high frequency and the equivalent circuit.

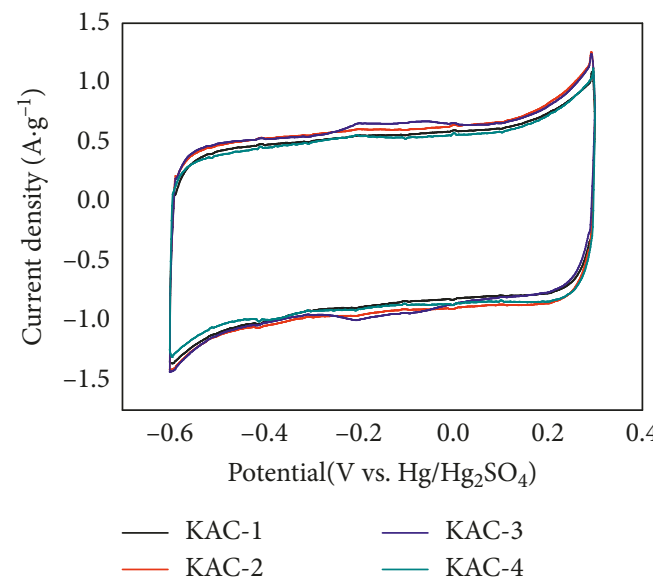

(a)

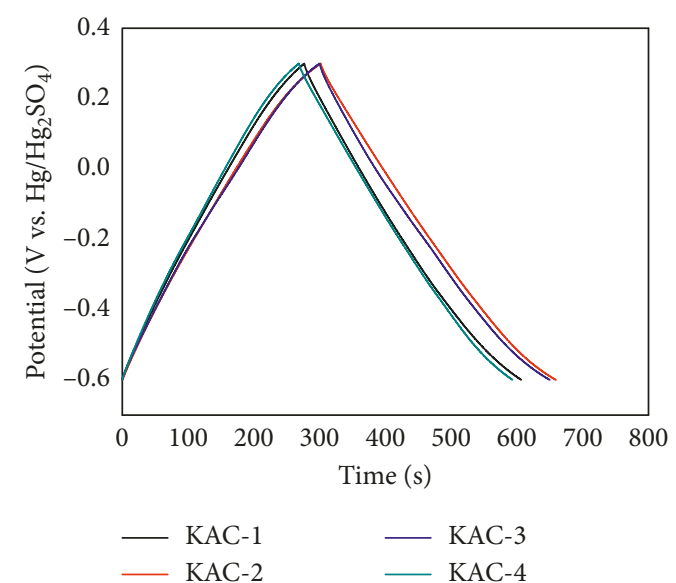

(b)

Figure 6: Continued. 


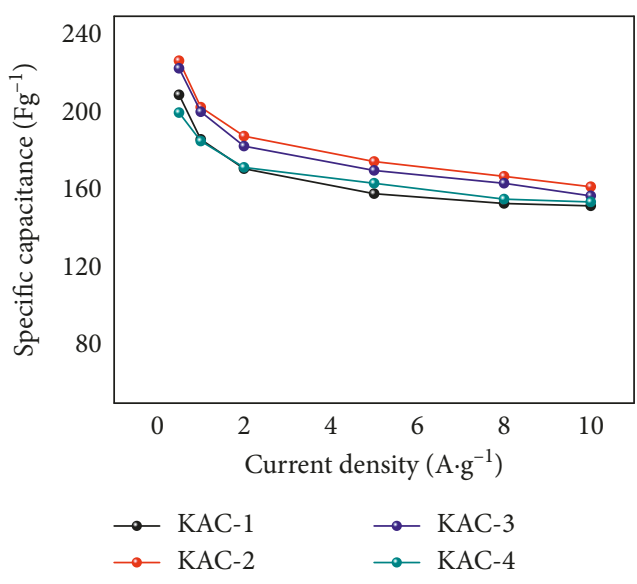

(c)

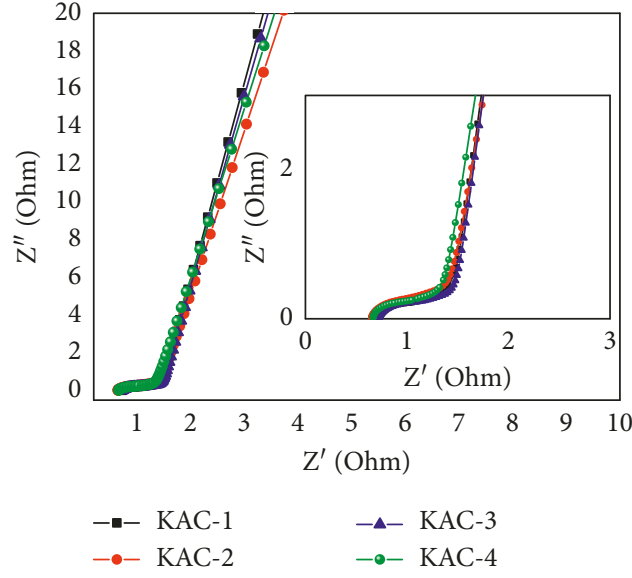

(d)

Figure 6: Electrochemical performance of $\mathrm{KAC}-1,2,3$, and 4 in $1 \mathrm{M} \mathrm{H}_{2} \mathrm{SO}_{4}$ aqueous solution. (a) CV curves at the scan rate of $5 \mathrm{mV} / \mathrm{s}$, (b) GCD curves at $0.5 \mathrm{~A} / \mathrm{g}$, (c) specific capacitances under different current densities calculated from GCD data, and (d) Nyquist plots of the achieved samples, the inset images showed enlarged impedance at the high frequency.

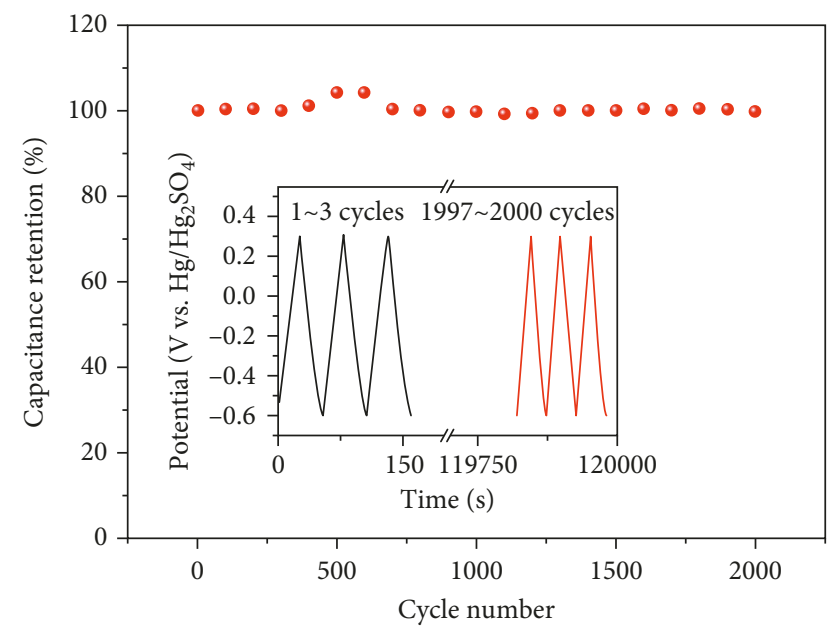

Figure 7: Cycling performance of KAC-700 under $5 \mathrm{~A} / \mathrm{g}$ for 2000 cycles. The inset image shows the GCD curves in the first and last 3 cycles.

micropores is elevated compared with other KAC counterparts, indicating the better rate ability. The decreased $\mathrm{O}$ content and improved electrical conductivity benefit the charge transport especially at the high rate.

\section{Conclusions}

In summary, we have prepared the hierarchically porous ACs from the Konjac sponge precursor. Upon $\mathrm{KOH}$ activation, the KAC samples inherit the lamellar morphology of the raw materials and possess coexisted micro/mesopores with narrow size distribution. Remarkably, graphene-like layers are observed in KAC-based samples, with the stacking distance comparable to the size of the electrolyte ion. KAC700 with rich $\mathrm{O}$ doping showed the highest specific capacitance owing to the largest ion accessible microporous volume with the optimized pore size. KAC-900 and KAC-4 possessed superior rate capability with the plentiful mesopores. Taking KAC-700 as an example, excellent cycling stability was obtained with only $0.4 \%$ decay of original capacitance under the current density of $5 \mathrm{~A} / \mathrm{g}$. The abundant source and simple synthetic procedure guarantee the scale-up production of such KAC materials, which would become novel and promising electrode materials for SC devices. The results achieved in this study can serve as guidance for the design and development of ACs with desirable porous structure, graphitized microstructure, and high SC performance.

\section{Data Availability}

The data used to support the findings of this study are available from the corresponding author upon request.

\section{Conflicts of Interest}

The authors declare that they have no conflicts of interest.

\section{Acknowledgments}

This work was supported by the National Natural Science Foundation of China (grant number 21703064) and the Ministry of Education of the People's Republic of China (grant number 2017MS046).

\section{Supplementary Materials}

Figure S1. TEM images of UAC samples under different magnifications. Figure S2. Transmission electron microscopy (TEM) images of (a and d) KAC-1, (b and e) KAC-2 and ( $c$ and f) KAC-4. Figure S3. Transmission electron microscopy (TEM) images of (a) KAC-700, (b) KAC-800 and (c) KAC-900, with the related digital micrograph showing the lateral distance information, the numbers demonstrated the lateral distance in the selected area, scale bar $=10 \mathrm{~nm}$. Figure S4. TEM images of (a) KAC-1, 
(b) KAC-2 and (c) KAC-4, with the related digital micrograph showing the lateral distance information, the numbers demonstrated the lateral distance in the selected area, scale bar $=10 \mathrm{~nm}$. Fig S5. Selected-area electron diffraction pattern of (a) KAC-700 and (b) KAC-4. Figure S6. O1s spectra of KAC based samples. Figure S7. CV curves of KAC based materials under scan rates of $1 \mathrm{mV} / \mathrm{s}, 5 \mathrm{mV} / \mathrm{s}, 10 \mathrm{mV} / \mathrm{s}, 20$ $\mathrm{mV} / \mathrm{s}, 50 \mathrm{mV} / \mathrm{s}, 100 \mathrm{mV} / \mathrm{s}$. Figure $\mathrm{S} 8$. GCD curves of KAC based materials under the current densities of $0.5 \mathrm{~A} / \mathrm{g}, 1 \mathrm{~A} / \mathrm{g}, 2$ A/g, $5 \mathrm{~A} / \mathrm{g}, 8 \mathrm{~A} / \mathrm{g}$ and $10 \mathrm{~A} / \mathrm{g}$. Figure S9. GCD curves (a) and the calculated specific capacitance (b) of UAC sample under different current densities. Figure S10. The microporous specific surface area (SSAmic) based on DFT model (Left Y axis), the microporous volume and ratio between mesoporous and microporous volume (Vmes/Vmic) (Right $\mathrm{Y}$ axis) of KAC based samples. Table S1. Elemental analysis results (atomic\%) based XPS data. Table S2. The specific capacitance calculated from the discharging curves of KAC based samples and the capacitance retention under $10 \mathrm{~A} / \mathrm{g}$ compared with that of $0.5 \mathrm{~A} / \mathrm{g}$. Table S3. Specific capacitance of KAC based matetials using three-electrode cells reported in literatures. (Supplementary Materials)

\section{References}

[1] P. Simon and Y. Gogotsi, "Materials for electrochemical capacitors," Nature Materials, vol. 7, no. 11, pp. 845-854, 2008.

[2] Y. Wang, Y. Song, and Y. Xia, "Electrochemical capacitors: mechanism, materials, systems, characterization and applications," Chemical Society Reviews, vol. 45, no. 21, pp. 5925-5950, 2016.

[3] S. Dutta, A. Bhaumik, and K. C. W. Wu, "Hierarchically porous carbon derived from polymers and biomass: effect of interconnected pores on energy applications," Energy and Environmental Science, vol. 7, no. 11, pp. 3574-3592, 2014.

[4] B. E. Conway, Electrochemical Supercapacitors: Scientific Fundamentals and Technological Applications, Springer Science \& Business Media, Berlin, Germany, 2013.

[5] H. Ji, X. Zhao, Z. Qiao et al., "Capacitance of carbon-based electrical double-layer capacitors," Nature Communications, vol. 5, no. 1, p. 3317, 2014.

[6] M. Yang, Y. Zhong, J. Bao et al., "Achieving battery-level energy density by constructing aqueous carbonaceous supercapacitors with hierarchical porous $\mathrm{N}$-rich carbon materials," Journal of Materials Chemistry A, vol. 3, no. 21, pp. 11387-11394, 2015.

[7] J. Y. Hwang, M. Li, M. F. El-Kady, and R. B. Kaner, "Nextgeneration activated carbon supercapacitors: a simple step in electrode processing leads to remarkable gains in energy density," Advanced Functional Materials, vol. 27, no. 15, article 1605745, 2017.

[8] Z. Zhitao, W. Lie, L. Yiming et al., "Nitrogen-doped coresheath carbon nanotube array for highly stretchable supercapacitor," Advanced Energy Materials, vol. 7, no. 5, article 1601814, 2017.

[9] J. Li, J. Tang, J. Yuan et al., "Enlarging energy density of supercapacitors using unequal graphene electrodes and ionic liquid electrolyte," Electrochimica Acta, vol. 258, pp. 10531058, 2017.

[10] R. R. Salunkhe, Y. Kamachi, N. L. Torad et al., "Fabrication of symmetric supercapacitors based on MOF-derived nanoporous carbons," Journal of Materials Chemistry A, vol. 2, no. 46, pp. 19848-19854, 2014.

[11] J. Yang, H. Wu, M. Zhu et al., "Optimized mesopores enabling enhanced rate performance in novel ultrahigh surface area meso-/microporous carbon for supercapacitors," Nano Energy, vol. 33, pp. 453-461, 2017.

[12] M. Oschatz, S. Boukhalfa, W. Nickel et al., "Carbide-derived carbon aerogels with tunable pore structure as versatile electrode material in high power supercapacitors," Carbon, vol. 113, pp. 283-291, 2017.

[13] B. Li, F. Dai, Q. Xiao et al., "Nitrogen-doped activated carbon for a high energy hybrid supercapacitor," Energy and Environmental Science, vol. 9, no. 1, pp. 102-106, 2016.

[14] T. Liu, F. Zhang, Y. Song, and Y. Li, "Revitalizing carbon supercapacitor electrodes with hierarchical porous structures," Journal of Materials Chemistry A, vol. 5, no. 34, pp. 17705-17733, 2017.

[15] K. Lee, Y. Yoon, Y. Cho et al., "Tunable sub-nanopores of graphene flake interlayers with conductive molecular linkers for supercapacitors," ACS Nano, vol. 10, no. 7, pp. 6799-6807, 2016.

[16] B. François, P. Volker, B. Andrea, and F. Elzbieta, "Carbons and electrolytes for advanced supercapacitors," Advanced Materials, vol. 26, no. 14, pp. 2219-2251, 2014.

[17] H. Liu, H. Song, X. Chen, S. Zhang, J. Zhou, and Z. Ma, "Effects of nitrogen- and oxygen-containing functional groups of activated carbon nanotubes on the electrochemical performance in supercapacitors," Journal of Power Sources, vol. 285, pp. 303-309, 2015.

[18] Y. Li, G. Wang, T. Wei, Z. Fan, and P. Yan, "Nitrogen and sulfur co-doped porous carbon nanosheets derived from willow catkin for supercapacitors," Nano Energy, vol. 19, pp. 165-175, 2016.

[19] B. Chang, W. Shi, S. Han et al., "N-rich porous carbons with a high graphitization degree and multiscale pore network for boosting high-rate supercapacitor with ultrafast charging," Chemical Engineering Journal, vol. 350, pp. 585-598, 2018.

[20] C. Xue, F. Yang, E. Wang et al., "Nanosized graphitic carbon with balanced micro/mesoporosity for robust supercapacitor with superior volumetric capacitance and cyclic performance," Electrochimica Acta, vol. 271, pp. 406-416, 2018.

[21] A. M. Abioye and F. N. Ani, "Recent development in the production of activated carbon electrodes from agricultural waste biomass for supercapacitors: a review," Renewable and Sustainable Energy Reviews, vol. 52, pp. 1282-1293, 2015.

[22] X. Tian, H. Ma, Z. Li et al., "Flute type micropores activated carbon from cotton stalk for high performance supercapacitors," Journal of Power Sources, vol. 359, pp. 88-96, 2017.

[23] G. Zhao, C. Chen, D. Yu et al., "One-step production of O-N-S co-doped three-dimensional hierarchical porous carbons for high-performance supercapacitors," Nano Energy, vol. 47, pp. 547-555, 2018.

[24] X. Teng, C. Ma, C. Ge et al., "Green synthesis of nitrogendoped carbon dots from konjac flour with "off-on" fluorescence by $\mathrm{Fe}^{3+}$ and 1-lysine for bioimaging," Journal of $\mathrm{Ma}$ terials Chemistry B, vol. 2, pp. 4631-4639, 2014.

[25] L. H. Cheng, A. Abd Karim, M. H. Norziah, and C. C. Seow, "Modification of the microstructural and physical properties of konjac glucomannan-based films by alkali and sodium carboxymethylcellulose," Food Research International, vol. 35, no. 9, pp. 829-836, 2002.

[26] Q. Li, X. Bai, Q. Meng et al., "Porous biochar generated from natural Amorphophallus konjac for high performance 
supercapacitors," Applied Surface Science, vol. 448, pp. 16-22, 2018.

[27] J. Hou, K. Jiang, R. Wei et al., "Popcorn-derived porous carbon flakes with an ultrahigh specific surface area for superior performance supercapacitors," ACS Applied Materials and Interfaces, vol. 9, no. 36, pp. 30626-30634, 2017.

[28] H. Zhu, F. Shen, W. Luo et al., "Low temperature carbonization of cellulose nanocrystals for high performance carbon anode of sodium-ion batteries," Nano Energy, vol. 33, pp. 37-44, 2017.

[29] Y. Zhu, S. Murali, M. D. Stoller et al., "Carbon-based supercapacitors produced by activation of graphene," Science, vol. 332, no. 6037, pp. 1537-1541, 2011.

[30] E. Raymundo-Piñero, P. Azaïs, T. Cacciaguerra et al., " $\mathrm{KOH}$ and $\mathrm{NaOH}$ activation mechanisms of multiwalled carbon nanotubes with different structural organisation," Carbon, vol. 43, no. 4, pp. 786-795, 2005.

[31] A. Sadezky, H. Muckenhuber, H. Grothe, R. Niessner, and U. Pöschl, "Raman microspectroscopy of soot and related carbonaceous materials: spectral analysis and structural information," Carbon, vol. 43, no. 8, pp. 1731-1742, 2005.

[32] X. Gao, W. Xing, J. Zhou et al., "Superior capacitive performance of active carbons derived from Enteromorpha prolifera," Electrochimica Acta, vol. 133, pp. 459-466, 2014.

[33] C. Emmenegger, P. Mauron, P. Sudan et al., "Investigation of electrochemical double-layer (ECDL) capacitors electrodes based on carbon nanotubes and activated carbon materials," Journal of Power Sources, vol. 124, no. 1, pp. 321-329, 2003.

[34] L. Shi-Yu, J. Meng, Z. Yan et al., "Chemically exfoliating biomass into a graphene-like porous active carbon with rational pore structure, good conductivity, and large surface area for high-performance supercapacitors," Advanced Energy Materials, vol. 8, no. 11, article 1702545, 2018.

[35] I. K. Moon, J. Lee, R. S. Ruoff, and H. Lee, "Reduced graphene oxide by chemical graphitization," Nature Communications, vol. 1, no. 6, p. 73, 2010.

[36] H. J. Denisa, S. Mykola, L. G. Qing, and B. T. J., "Combined effect of nitrogen- and oxygen-containing functional groups of microporous activated carbon on its electrochemical performance in supercapacitors," Advanced Functional Materials, vol. 19, no. 3, pp. 438-447, 2009.

[37] C. Wang, D. Wu, H. Wang et al., "A green and scalable route to yield porous carbon sheets from biomass for supercapacitors with high capacity," Journal of Materials Chemistry A, vol. 6, no. 3, pp. 1244-1254, 2018.

[38] B. Han, G. Cheng, E. Zhang, L. Zhang, and X. Wang, "Three dimensional hierarchically porous ZIF-8 derived carbon/LDH core-shell composite for high performance supercapacitors," Electrochimica Acta, vol. 263, pp. 391-399, 2018.

[39] C. Pean, B. Daffos, B. Rotenberg et al., "Confinement, desolvation, and electrosorption effects on the diffusion of ions in nanoporous carbon electrodes," Journal of the American Chemical Society, vol. 137, no. 39, pp. 12627-12632, 2015.

[40] M. Salanne, B. Rotenberg, K. Naoi et al., "Efficient storage mechanisms for building better supercapacitors," Nature Energy, vol. 1, no. 6, article 16070, 2016.

[41] M. Endo, T. Maeda, T. Takeda et al., "Capacitance and poresize distribution in aqueous and nonaqueous dlectrolytes using various activated carbon electrodes," Journal of the Electrochemical Society, vol. 148, no. 8, pp. A910-A914, 2001.

[42] D. Hulicova, M. Kodama, and H. Hatori, "Electrochemical performance of nitrogen-enriched carbons in aqueous and non-aqueous supercapacitors," Chemistry of Materials, vol. 18, no. 9, pp. 2318-2326, 2006.
[43] K. Urita, C. Urita, K. Fujita et al., "The ideal porous structure of EDLC carbon electrodes with extremely high capacitance," Nanoscale, vol. 9, no. 40, pp. 15643-15649, 2017.

[44] J. Hou, C. Cao, F. Idrees, and X. Ma, "Hierarchical porous nitrogen-doped carbon nanosheets derived from silk for ultrahigh-capacity battery anodes and supercapacitors," ACS Nano, vol. 9, no. 3, pp. 2556-2564, 2015.

[45] B. Liu, M. Yang, H. Chen et al., "Graphene-like porous carbon nanosheets derived from salvia splendens for high-rate performance supercapacitors," Journal of Power Sources, vol. 397, pp. 1-10, 2018.

[46] L. Sun, C. Tian, M. Li et al., "From coconut shell to porous graphene-like nanosheets for high-power supercapacitors," Journal of Materials Chemistry A, vol. 1, no. 21, pp. 6462-6470, 2013.

[47] M. Zhi, F. Yang, F. Meng et al., "Effects of pore structure on performance of an activated-carbon supercapacitor electrode recycled from scrap waste tires," ACS Sustainable Chemistry and Engineering, vol. 2, no. 7, pp. 1592-1598, 2014.

[48] H. Zhang, X. Zhang, and Y. Ma, "Enhanced capacitance supercapacitor electrodes from porous carbons with high mesoporous volume," Electrochimica Acta, vol. 184, pp. 347-355, 2015.

[49] W. Li, J. Liu, and D. Zhao, "Mesoporous materials for energy conversion and storage devices," Nature Reviews Materials, vol. 1, no. 6, article 16023, 2016.

[50] S. Yang, X. Wu, C. Chen et al., "Spherical $[\alpha]-\mathrm{Ni}(\mathrm{OH})_{2}$ nanoarchitecture grown on graphene as advanced electrochemical pseudocapacitor materials," Chemical Communications, vol. 48, no. 22, pp. 2773-2775, 2012.

[51] Y. Lu, S. Zhang, J. Yin et al., "Mesoporous activated carbon materials with ultrahigh mesopore volume and effective specific surface area for high performance supercapacitors," Carbon, vol. 124, pp. 64-71, 2017.

[52] H. Feng, H. Hu, H. Dong et al., "Hierarchical structured carbon derived from bagasse wastes: a simple and efficient synthesis route and its improved electrochemical properties for high-performance supercapacitors," Journal of Power Sources, vol. 302, pp. 164-173, 2016. 


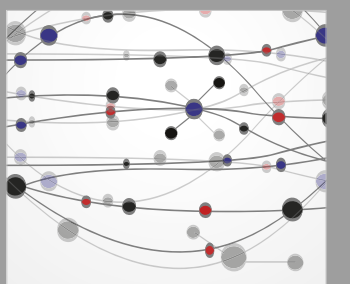

The Scientific World Journal
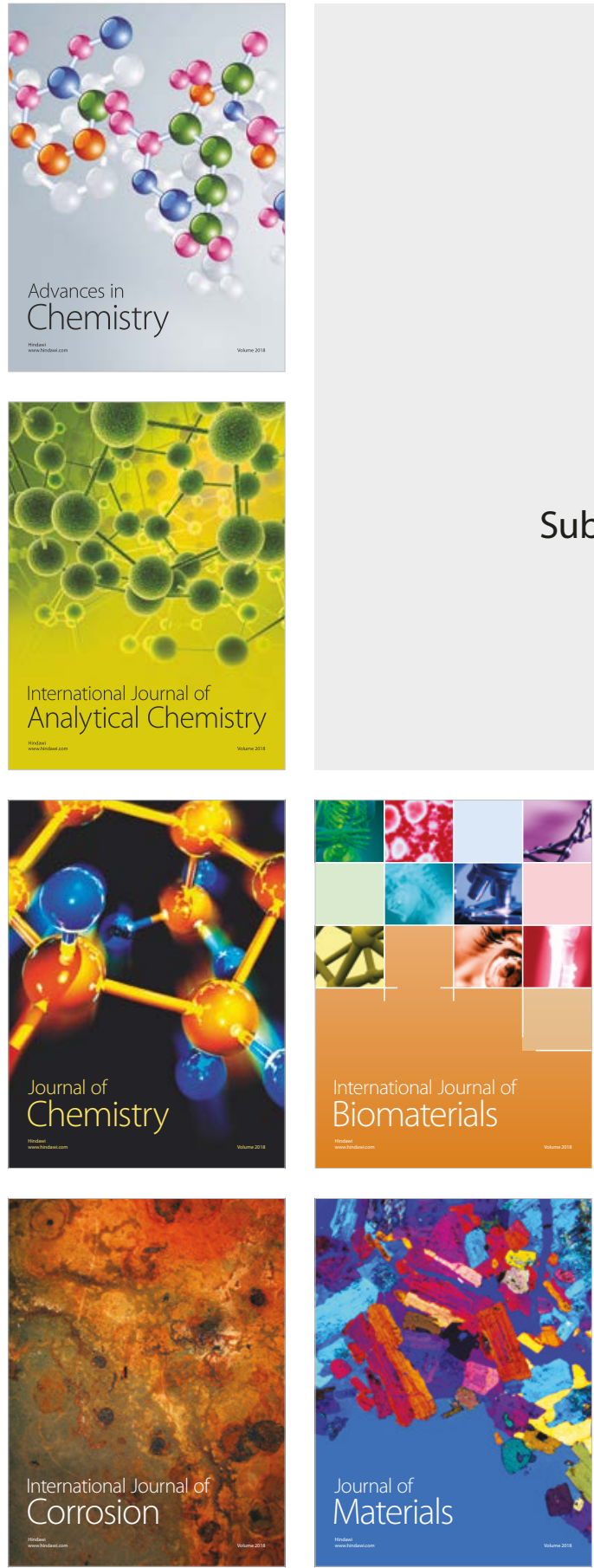

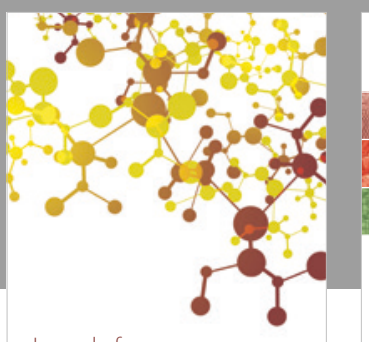

Journal of

Applied Chemistry
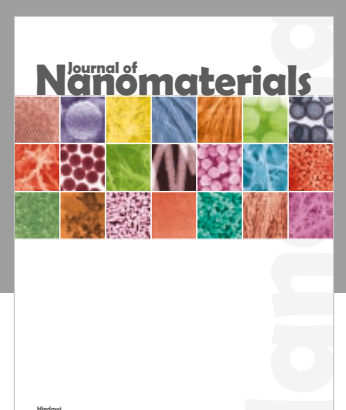

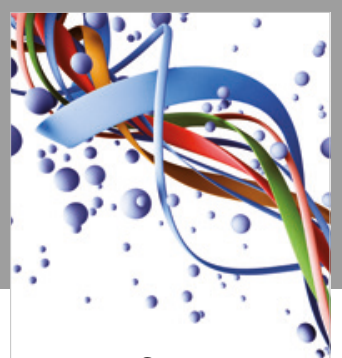

Scientifica

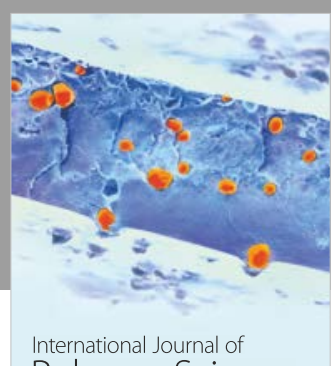

Polymer Science

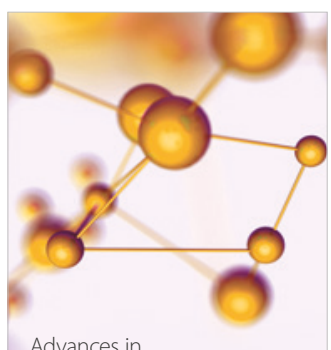

Physical Chemistry
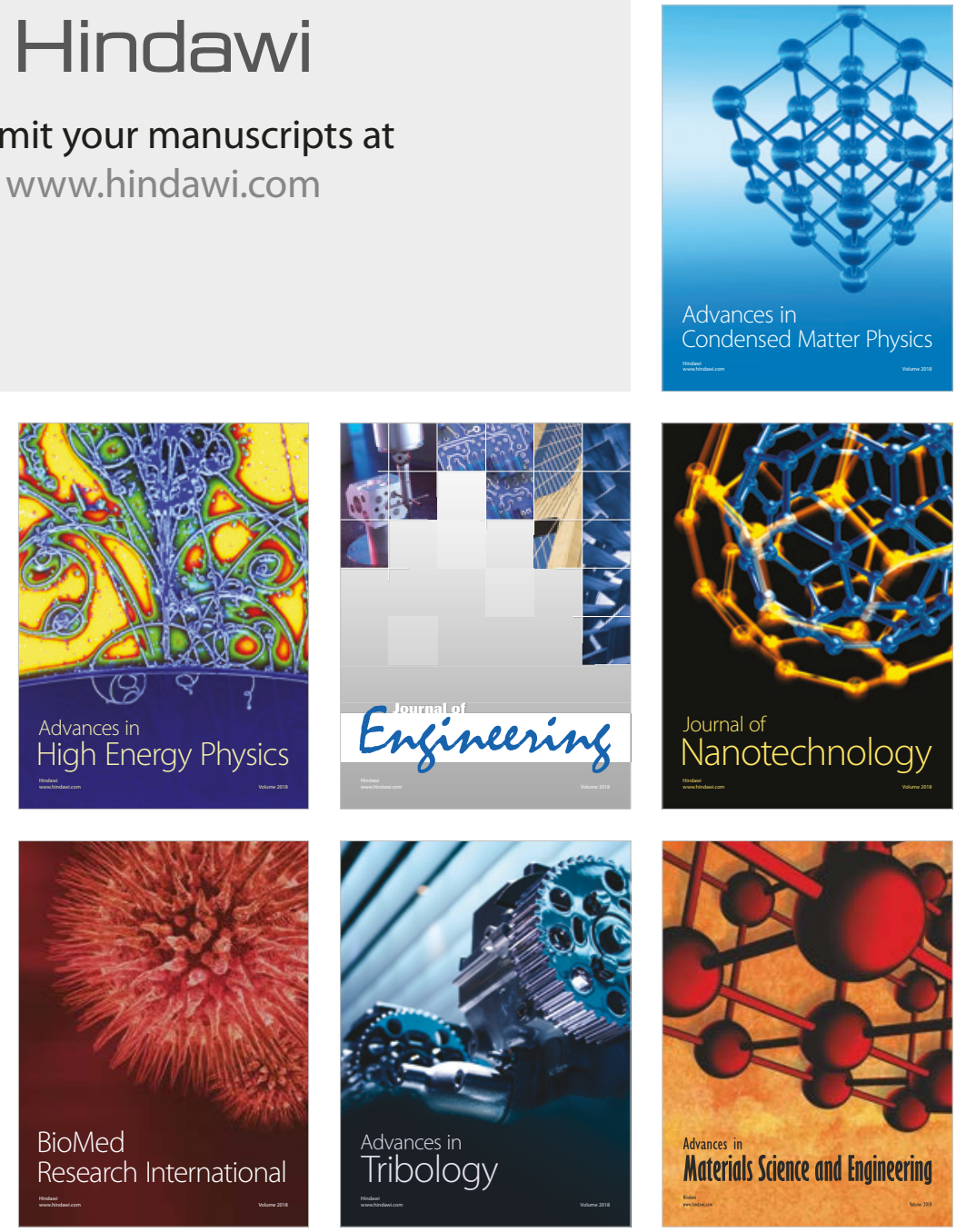